\title{
Metabolic indicators associated with non-communicable diseases deteriorated in the Coronavirus Disease 2019 outbreak: evidence from a two-center, retrospective, self-controlled study
}

Ting Xue

Fujian Medical University

\section{Lizhen Xu}

Fujian Medical University

\section{Yaqian Mao}

Fujian Medical University

Wei Lin

Fujian Medical University

Jixing Liang

Fujian Medical University

Huibin Huang

Fujian Medical University

Liantao Li

Fujian Medical University

Junping Wen

Fujian Medical University

Gang Chen ( $\nabla$ chengangfj@163.com )

Fujian Medical University

\section{Research Article}

Keywords: Non-communicable diseases, COVID-19, Blood lipid, Uric acid, Glycosylated hemoglobin

Posted Date: February 23rd, 2021

DOI: https://doi.org/10.21203/rs.3.rs-215093/v1

License: (c) (1) This work is licensed under a Creative Commons Attribution 4.0 International License. Read Full License 


\section{Abstract \\ Background}

The current double epidemic of non-communicable diseases (NCDs) and the 2019 coronavirus disease (COVID-19) and their vicious circle relationship causes adverse health effects at the population level and, at the same time, places a tremendous burden on the health care system. Our study aimed to investigate whether the metabolic indicators associated with NCDs in the general population have changed during the COVID-19 outbreak.

\section{Results}

We conducted a retrospective self-controlled study enrolling adult participants who received baseline test for metabolic indicators related to NCDs during January 1, 2019 and April 30, 2019 and were followed up on metabolic indicators in the same period in 2020. The follow-up total cholesterol was significantly increased than that of the baseline $(4.73(4.05,5.46) \mathrm{mmol} / \mathrm{L}$ vs $4.71(4.05$, $5.43) \mathrm{mmol} / \mathrm{L}, \mathrm{p}=0.019 ; \mathrm{n}=3379)$. Similar results were observed in triglyceride $(1.29(0.91,1.88) \mathrm{vs} 1.25(0.87,1.81) \mathrm{mmol} / \mathrm{L}, \mathrm{p}<$ $0.001 ; n=3381)$, uric acid $(330.0(272.0,397.0)$ vs $327.0(271.0,389.0) \mathrm{umol} / \mathrm{L}, \mathrm{p}<0.001 ; \mathrm{n}=3364)$, and glycosylated hemoglobin $(6.50(6.10,7.30)$ vs $6.50(6.10,7.20) \%, p=0.013 ; n=532)$. No significant difference was observed in low density lipoprotein, body mass index and blood pressure.

\section{Conclusions}

Metabolic indicators associated with non-communicable diseases deteriorated in the Coronavirus Disease 2019 outbreak. We should take action to prevent and control non-communicable diseases without delay.

\section{Strengths And Limitations Of The Study}

- This is, to our knowledge, the first study to explore multiple metabolic indicators associated with noncommunicable diseases in the general population on a large scale, offering the basis for the corresponding intervention strategy for the current and future public health emergencies.

- This is a self-controlled study, which could eliminate individual difference to a great extent.

- With no detailed information relating to particular changes in eating habits, physical activity, and psychological situation among the participants, we could not confirm which factor contributed the most to the deterioration of the metabolic indicators.

\section{Introduction}

At the end of 2019, the emergence of a new coronavirus caused the Coronavirus Disease 2019 (COVID-19) epidemic worldwide ${ }^{1}$. As of June 24, 2020, there were over nine million confirmed cases of COVID-19 and almost 478,000 deaths globally ${ }^{2}$. The number of confirmed cases of the COVID-19 is rising worldwide. With the lack of effective vaccines and specific drugs, many countries have quickly adopted quarantine, social distancing, community containment, and other measures to deal with this global public health emergency ${ }^{3-5}$. The Chinese government has implemented lockdown and social distancing measures since January 2020 and achieved preliminary success at the end of Apri $2020^{5,6}$. As of May 2, 2020, all provinces across the country have ceased the first-level response ${ }^{7}$. The prevention and control of the COVID-19 epidemic in China has changed from emergency to normal, with lockdown status ended and social distancing continued ${ }^{8}$. Due to the high prevalence of non-communicable diseases (NCDs) and the possible mutual deteriorating relationship between NCDs and COVID-19, we should now pay attention to whether the risk and control of NCDs have changed during the epidemic, and take corresponding measures.

There is increasing clinical evidence that NCDs related to metabolic syndrome, such as diabetes and hypertension, were the most common comorbidities among COVID-19 patients, and could significantly increase the severity and mortality ${ }^{9-11}$. Deteriorated 
metabolic indicators, including blood lipid, blood uric acid(UA), blood preesure(BP), blood glucose and body mass index(BMI), could directly or indirectly affect the progression of COVID-19 by increasing the risk of NCD s ${ }^{12-14}$. As the progression of COVID-19 is mainly dependent on the initial health status of an individual, the prevention and control of NCDs are of vital importance to reduce the harm of the COVID-19 epidemic currently and in the future. Meanwhile, NCDs are the leading causes of death worldwide, contributing to $73.4 \%$ of total deaths in $2017^{15}$. Hypertension and diabetes are the most common NCDs among Chinese adults, with $25.2 \%$ and $9.7 \%$ of Chinese adults suffering from hypertension and diabetes, respectively ${ }^{16}$. The prevention and control of NCDs could reduce the chronic complications related to disability and premature death, as well as the direct and indirect medical expenses related to them ${ }^{17,18}$.

It is worth noting that lifestyles may change greatly in the face of the threat of COVID-19, thereby affecting the risk and control of $\mathrm{NCDs}^{8,19-21}$. A recent analysis from mathematical modeling in India forecasted that lockdown would substantially increase glycosylated hemoglobin (HbA1c) and future diabetes-related complications ${ }^{22}$. Social distancing and COVID-19-related relevant negative news may adversely affect emotions, leading to behavior changes and physical health issues associated with NCDs ${ }^{23}$. Routine management of NCDs has been scaled down during the peak period of the COVID-19 epidemic. People at high risk for NCDs may have to delay their screening test, and patients with NCDs may discontinue treatment or change the treatment without the guidance of doctors, resulting in poor control.

To our knowledge, nevertheless, only a few studies focused on the risk of NCDs and its control during the COVID-19 outbreak. One study paid attention to weight change in Poland adults during the COVID-19 crises and found that almost 30\% experienced weight gain $^{19}$. The other studies focused on glycaemic control in diabetes during the restrictions due to COVID-19 pandemics and unexpectedly found no results indicating deterioration ${ }^{4,24-26}$. However, the sample size of those studies was small, and those who represent patients with non-autoimmune forms of diabetes were underrepresented.

The current double epidemic of NCDs and COVID-19 and their vicious circle relationship causes adverse health effects at the population level and, at the same time, places a tremendous burden on the health care system. The present retrospective selfcontrolled study aimed to analyse more metabolic indicators associated with NCDs in the general population on a large scale, offering the basis for the corresponding intervention strategy for the prevention and control of NCDs during the COVID-19 outbreak and the subsequent period.

\section{Methods}

\section{Study design, setting and participants}

We conducted a retrospective, self-controlled study. The study was approved by the Ethics Committee of Fujian Provincial Hospital (Approval ID K2020-06-015), and all methods were carried out in accordance with Declaration of Helsinki. Due to the retrospective nature of the study, informed consent was waived by the Ethics Committee of Fujian Provincial Hospital. Participants' information has been anonymized since the data collection stage.

We collected data from the electronic medical record system of two tertial hospitals. Individuals aged 18 years old and above with baseline and follower-up metabolic indicators associated with NCDs were enrolled in our retrospective self-controlled study. Emergency patients and inpatients were excluded to rule out the potential effects of stress on metabolism. Baseline metabolic data including total cholesterol (TC), low density lipoprotein (LDL), triglyceride (TG), UA, HbA1c, BMI, systolic blood pressure (SBP), and diastolic blood pressure (DBP) during January 1, 2019 and April 30, 2019, were compared with the follow-up data in the same period of 2020, the peak period of COVID-19 epidemic in China.

\section{Patient and Public Involvement statement}

There were no patient and public involved due to the retrospective nature of the study.

\section{Measurement}


Weight and height were measured using an ultrasonic, when participants were barefoot and worn light clothing. BMI was calculated as weight in kilograms divided by height in meters squared $(\mathrm{kg} / \mathrm{m} 2)$. Blood pressure was measured three times on the right arm using an automatic sphygmomanometer after 5 minutes of seated rest and was recorded as the average of the last two blood pressure readings. TC, LDL, TG, and UA were quantified using an enzymatic colorimetric assay. HbA1c was measured by high-performance liquid chromatography. Participants aged $18-44,45-64$, and $>65$ years old were regarded as young, middle-aged, and aged.

\section{Statistical methods}

All statistical analyses were conducted with SPSS Statistics for Windows, Version 25.0 (Armonk, NY: IBM Corp). Data are presented as the number (percentage) for categorical variables and the median (interquartile range (IQR)) for continuous variables that are not normally distributed. Paired-samples T-test and Wilcoxon signed-rank test were performed to check the differences of paired data that are normally distributed and abnormally distributed, respectively. All tests were two-sided, and $p<0.05$ was considered statistically significant.

\section{Results}

\section{Demographic characteristics}

The demographic characteristics of the studied population were presented in Table 1. More than three thousand participants were analyzed for TC $(n=3379)$, LDL $(n=3341)$, triglyceride $(T G)(n=3381)$, and UA ( $n=3364)$. Middle-aged account for almost half. A total of 532 participants were analysed for $\mathrm{HbA1c}$, with most were middle-aged/aged and male. For BMI $囚 \mathrm{n}=445)$ and $B P \square n=463)$, more than four hundred participants were analysed, most of whom were young and female.

\section{Metabolic indicators}

The comparison of baseline and follow-up metabolic indicators were shown in Table 2. The follow-up TC $(4.73(4.05,5.46)$ $\mathrm{mmol} / \mathrm{L})$ was significantly increased than that of the baseline $(4.71(4.05,5.43) \mathrm{mmol} / \mathrm{L}, \mathrm{p}=0.019)$. Similar results were observed for TG $(1.29(0.91,1.88)$ vs $1.25(0.87,1.81) \mathrm{mmol} / \mathrm{L}, \mathrm{p}<0.001)$, UA $(330.0(272.0,397.0)$ vs $327.0(271.0,389.0)$ umol/L, $\mathrm{p}<0.001)$ and $\mathrm{HbA} 1 \mathrm{c}(6.50(6.10,7.30)$ vs $6.50(6.10,7.20) \%, \mathrm{p}=0.013)$. There was no significantly statistical difference between the follow up and baseline LDL $(3.00(2.40,3.67)$ vs $3.04(2.44,3.70), p=0.169)$, BMI $(22.86(20.72,24.88)$ vs $22.88(20.89,24.97)$, $p=0.976)$, SBP $(120.0(111.0,129.0)$ vs $120.0(111.0,130.0), p=0.896)$, and $\operatorname{DBP}(73.0(67.0,81.0)$ vs $73.0(67.0,81.0), p=0.724)$.

\section{Discussion}

The main findings of the present study were that metabolic indicators, including TC, TG, UA, and HbA1c, were significantly increased during the outbreak of COVID-19. Nevertheless, no statistical difference was observed in LDL, BMI, and BP.

Our results provided evidence that metabolic indicators associated with NCDs deteriorated during the COVID-19 outbreak in China. With the initiation of the first-level response to prevent the spread of COVID-19 during January 2020 and April 2020 in China ${ }^{5,7}$, the impacts of social distancing and community containment on lifestyles may be among the most critical factors in the increase of TC, TG, UA, and HbA1c. People tend to eat and snack more during home quarantine conditions ${ }^{19}$. As lockdown caused problems in the food supply chain and economic recession, the consumption of processed foods characterized by high fat, high sugar, and high salt increased due to easy availability, storage, and use $8,20,22$. These dietary changes will lead to metabolic disorders related to NCDs in the COVID-19 outbreak and the subsequent period. Meanwhile, the closure of gyms, swimming pools, and exercise clubs, in addition to home quarantine, will inevitably reduce opportunities to exercise ${ }^{27}$. A longitudinal study demonstrated that time spent in sports activities decreased and the screen time increased in the COVID-19 storm ${ }^{21}$. This phenomenon is detrimental to health because physical activity is critical to control the symptoms and risk factors of $\mathrm{NCDs}^{28}$. Furthermore, fear of catching the virus, worrying about family, social isolation, financial pressure, rumors everywhere, and information overload lead to increased stress and anxiety levels, which will result in behaviour changes and physical health issues associated with NCDs ${ }^{23}$. Finally, as precious healthcare resources were diverted towards the prevention and control of COVID-19 epidemics, and to avoid crosscontamination in hospitals, routine management of NCDs has been scaled down during the peak period of the COVID-19 epidemic. 
Patients with NCDs who take angiotensin receptor blockers or angiotensin-converting enzyme Inhibitors regularly may stop their treatment without their doctor's guidance for fear that these medications will increase the risk of COVID-19 infection through upregulation ACE2, which could lead to uncontrolled illness.

This is, as far as we know, the first study to explore blood lipid and uric acid levels among the general population during the outbreak of a public health emergency of international concern declared by the World Health Organization and proved that blood lipid and uric acid levels were increased. Though there is a lack of clinical evidence about the association between hyperlipidaemia/hyperuricaemia and COVID-19, it seems that metabolic disorders may indirectly affect the progression of COVID19 through increasing the risk of NCDs. Moreover, lipids and cholesterol-rich membrane microdomains are essential for coronavirus entry into human cells ${ }^{29}$. High amounts of intracellular cholesterol and fatty acids are essential for the formation of the replication complex of COVID-1929. In this context, strengthening the screening and control of hyperlipidemia may have a double beneficial effect by reducing the NCD risk and interfering with COVID-19.

Our result that $\mathrm{HbA} 1 \mathrm{c}$ was elevated in the COVID-19 storm provided further evidence for the prediction of previous arithmetic models ${ }^{22}$. However, previous studies focused on the glycaemic control in diabetes during the restrictions due to COVID-19 pandemics found no deteriorated results ${ }^{4}$ 24-26. These different results may be explained as follows. First, the sample size of previous studies is small $(n=13,33,55$, and 147), and patients with type 1 diabetes accounts for more than 90 percent of the studied population 4 24-26. Those representing patients with non-autoimmune forms of diabetes who were underrepresented in the previous study. Second, the patients in previous studies used both continuous glucose monitoring and platforms for remote data sharing and were younger (median/average age $<45$ years old) than those in our study (median age 64 years old) ${ }^{4,24-26}$. We speculate that the patients in previous studies may have better health literacy and compliance to avoid metabolic deteriorattion in the COVID-19 outbreak. Our study enrolled the general population, including healthy people and patients with NCDs, with a larger sample size, and thus the conclusion may be more general. Moreover, our research time is longer than that of previous studies. The present study compared metabolic changes during the peak period of the COVID-19 epidemic and the same period of last year, not the short period of lockdown and pre-lockdown. The impact of the COVID-19 epidemic on NCDs and its risks is existed not only during the strict lockdown period but also early on in the outbreak when fear was the prevailing emotion and the extended period of subsequent economic downturn and social distancing after lockdown. It will probably take time to fully evaluate the impact of the COVID-19 outbreak on the NCDs risks and control.

It is worth noting that we did not find significant differences in BMI and BP between the time of the COVID-19 outbreak and the same period last year. These results may be due to the small sample of BMI and BP of the participants in our study; additionally, most of them are young people who may have better health literacy and compliance to prevent metabolic deterioration in the COVID-19 storm.

The COVID-19 pandemic is expected to be long drawn. To meet the challenge that metabolic indicators associated with NCDs deteriorated during the COVID-19 outbreak, we should take action to prevent and control NCDs without delay. We can focus on the following aspects to avoid the adverse effects of the outbreak on the general population. First of all, as the primary care system plays a vital role in the prevention and control of NCDs, a hierarchical medical system should be further implemented, and medical education for general practitioners should be enhanced. General practitioners should not only focus on the prevention and control of infectious disease but also on NCDs within the context of their community. Metabolic indicators associated with NCDs should be further monitored by general practitioners during the outbreak to return them to normal as soon as possible, thus reducing the morbidity and mortality rates of NCDs. Telemedicine consults should be implemented where possible, and home delivery services should be arranged for essential medications. Second, with the development of $5^{\text {th }}$ generation wireless systems, high-quality massive open online courses on health education should be developed by health workers to promote healthy behaviours at home. Health education and health-promoting behaviours have proven beneficial for metabolic management ${ }^{30}$. In addition, the government should take measures to ensure easy access to healthy foods for the population and should discourage the use or consumption of unhealthy products. Finally, to alleviate the psychological impact of the pandemic, information sharing should be enhanced, and proper psychological guidance should be implemented.

The main limitation of our study is that this study only reflected changes in metabolic indicators associated with NCDs during the COVID-19 outbreak. With no detailed information relating to particular changes in eating habits, physical activity, and

Page 5/9 
psychological situation among the participants, we could not confirm which factor contributed the most to the deterioration of the metabolic indicators. In addition, these data referred to an adult cohort, including healthy people and patients with NCDs.

Information on medical history that may affect the results was not recorded. More studies are necessary to fully evaluate the impact that COVID-19 has had on the health status at the population level, and going forward, it is of vital importance to collect information to better prevent and control NCDs.

In conclusion, metabolic indicators associated with NCDs deteriorated in the COVID-19 outbreak. It is a crucial time to strengthen action on prevention and control of NCDs to minimize the morbidity and mortality rates of COVID-19 in the short-term and reduce total morbidity and mortality rates of NCDs in the long-term, avoiding adding on to the burden of countries' healthcare systems.

\section{Abbreviations}

BMI, body mass index; DBP, diastolic blood pressure; HbA1c, glycosylated hemoglobin; IQR, interquartile range; LDL, low density lipoprotein; SBP, systolic blood pressure; TC, total cholesterol; TG, triglyceride; UA, uric acid.

\section{Declarations}

\section{Ethics approval and consent to participate}

The study was approved by the Ethics Committee of Fujian Provincial Hospital (Approval ID K2020-06-015). Due to the retrospective nature of the study, informed consent was waived by the Ethics Committee of Fujian Provincial Hospital.

\section{Consent for publication}

Not applicable.

\section{Availability of data and materials}

The datasets used and/or analyzed during the current study are available from the corresponding author on reasonable request.

\section{Competing Interests:}

None declared.

\section{Funding:}

None.

\section{Authors' contributions}

$X, T$ wrote the first draft of the manuscript. $X, T, X, L Z, M, Y Q, L, W, L, J X, H, H B$, and $L, L T$ collected the data and conducted analyses. $C, G$ design the study, revised the manuscript, reviewed the results, and contributed to the discussion. C,G and W,JP conceived of the research idea. C,G is the guarantors of this work and, as such, had full access to all the data in the study and takes responsibility for the integrity of the data and the accuracy of the data analysis. All authors reviewed the manuscript. All authors read and approved the final manuscript.

\section{Acknowledgments}

We greatly appreciate the efforts of all the hospital employees and their families at the Fujian Provincial Hospital and Fujian Provincial Hospital South Branch, who are working tirelessly during this outbreak.

\section{References}

1. Huang C, Wang Y, Li X, Ren L, Zhao J, Hu Y, et al. Clinical features of patients infected with 2019 novel coronavirus in Wuhan, China. Lancet. 2020;395(10223):497-506. https://doi.org/10.1016/S0140-6736(20)30183-5. 
2. Coronavirus Resource Center, John Hopkins University \& Medicine. https://coronavirus.jhu.edu/map.html; 2020[accessed 8 Augus 2020].

3. Hall G, Laddu DR, Phillips SA, Lavie CJ, Arena R. A tale of two pandemics: How will COVID-19 and global trends in physical inactivity and sedentary behavior affect one another? Progress in cardiovascular diseases. 2020; https://doi.org/10.1016/j.pcad.2020.04.005.

4. Tornese G, Ceconi V, Monasta L, Carletti C, Faleschini E, Barbi E. Glycemic Control in Type 1 Diabetes Mellitus During COVID-19 Quarantine and the Role of In-Home Physical Activity. Diabetes Technol Ther. 2020; 22:462-

7https://doi.org/10.1089/dia.2020.0169.

5. Wilder-Smith A, Freedman DO. Isolation, quarantine, social distancing and community containment: pivotal role for old-style public health measures in the novel coronavirus (2019-nCoV) outbreak. J Travel Med. 2020; https://doi.org/10.1093/jtm/taaa020.

6. National Health Commission of the People's Republic of China. http://www.nhc.gov.cn/xcs/yqtb/list_gzbd.shtml.2020[accessed on 24 Jun 2020].

7. Peoples Network. Summary of national emergency response levels: 8 provinces are at the second level and 21 provinces are at the third level, http://society.people.com.cn/n1/2020/0505/c1008-31697373.html. 2020[accessed 8 Augus 2020].

8. Bureau of Disease Control and Prevention of the People's Republic of China. Interpretation of the "Nutrition and health guidance for key populations during the COVID-19 epidemic", http://www.nhc.gov.cn/jkj/s5899tg/202005/aa359e8f8e2648e7a474e7b38aacb4b0.shtml.2020[accessed 8 Augus 2020].

9. Zheng Z, Peng F, Xu B, Zhao J, Liu H, Peng J, et al. Risk factors of critical \& mortal COVID-19 cases: A systematic literature review and meta-analysis. J Infect. 2020; https://doi.org/10.1016/j.jinf.2020.04.021.

10. Yang J, Zheng Y, Gou X, Pu K, Chen Z, Guo Q, et al. Prevalence of comorbidities and its effects in patients infected with SARSCoV-2: a systematic review and meta-analysis. Int J Infect Dis. 2020; 94:91-5https://doi.org/10.1016/j.ijid.2020.03.017.

11. Liu H, Chen S, Liu M, Nie H, Lu H. Comorbid Chronic Diseases are Strongly Correlated with Disease Severity among COVID-19 Patients: A Systematic Review and Meta-Analysis. Aging and disease. 2020; 11:668-

78https://doi.org/10.14336/ad.2020.0502.

12. Kalligeros M, Shehadeh F, Mylona EK, Benitez G, Beckwith CG, Chan PA, et al. Association of Obesity with Disease Severity among Patients with COVID-19. Obesity (Silver Spring). 2020; https://doi.org/10.1002/oby.22859.

13. Wang Z, Du Z, Zhu F. Glycosylated hemoglobin is associated with systemic inflammation, hypercoagulability, and prognosis of COVID-19 patients. Diabetes Res Clin Pract. 2020; 164:108214https://doi.org/10.1016/j.diabres.2020.108214.

14. Vicenzi M, Di Cosola R, Ruscica M, Ratti A, Rota I, Rota F, et al. The liaison between respiratory failure and high blood pressure: evidence from COVID-19 patients. The European respiratory journal. 2020; https://doi.org/10.1183/13993003.01157-2020.

15. Institute for Health Metrics and Evaluation of the United States. Global, regional, and national age-sex-specific mortality for 282 causes of death in 195 countries and territories, 1980-2017: a systematic analysis for the Global Burden of Disease Study 2017. Lancet (London, England). 2018; 392:1736-88https://doi.org/10.1016/s0140-6736(18)32203-7.

16. Bureau of Disease Control and Prevention of the People's Republic of China. Report on Nutrition and Chronic Disease Status of Chinese Residents (2015), http://www.nhc.gov.cn/jkj/s5879/201506/4505528e65f3460fb88685081ff158a2.shtml. 2020[accessed 8 Augus 2020].

17. International Diabetes Federation. IDF DIABETES ATLAS, Ninth edition 2019. https://diabetesatlas.org/upload/resources/material/20200302_133351_IDFATLAS9e-final-web.pdf\#page=38\&zoom=auto. 2020[accessed 8 Augus 2020].

18. The Worldbank. Toward a Healthy and Harmonious Life in China: Stemming the Rising Tide of Non-Communicable Diseases. https://www.worldbank.org/content/dam/Worldbank/document/NCD_report_en.pdf. 2020[accessed 8 Augus 2020].

19. Sidor A, Rzymski P. Dietary Choices and Habits during COVID-19 Lockdown: Experience from Poland. Nutrients. $2020 ; 12$. https://doi.org/10.3390/nu12061657.

20. Martinez-Ferran M, de la Guía-Galipienso F, Sanchis-Gomar F, Pareja-Galeano H. Metabolic Impacts of Confinement during the COVID-19 Pandemic Due to Modified Diet and Physical Activity Habits. Nutrients. 2020; 12. https://doi.org/10.3390/nu12061549. 
21. Pietrobelli A, Pecoraro L, Ferruzzi A, Heo M, Faith M, Zoller T, et al. Effects of COVID-19 Lockdown on Lifestyle Behaviors in Children with Obesity Living in Verona, Italy: A Longitudinal Study. Obesity (Silver Spring). 2020;

https://doi.org/10.1002/oby.22861.

22. Ghosal S, Sinha B, Majumder M, Misra A. Estimation of effects of nationwide lockdown for containing coronavirus infection on worsening of glycosylated haemoglobin and increase in diabetes-related complications: A simulation model using multivariate regression analysis. Diabetes \& metabolic syndrome. 2020; 14:319-23https://doi.org/10.1016/j.dsx.2020.03.014.

23. Abbas AM, Fathy SK, Fawzy AT, Salem AS, Shawky MS. The mutual effects of COVID-19 and obesity. Obesity medicine. 2020; 19:100250https://doi.org/10.1016/j.obmed.2020.100250.

24. Beato-Víbora PI. No deleterious effect of lockdown due to COVID-19 pandemic on glycaemic control, measured by glucose monitoring, in adults with type 1 diabetes. Diabetes Technol Ther. 2020; https://doi.org/10.1089/dia.2020.0184.

25. Bonora BM, Boscari F, Avogaro A, Bruttomesso D, Fadini GP. Glycaemic Control Among People with Type 1 Diabetes During Lockdown for the SARS-CoV-2 Outbreak in Italy. Diabetes therapy : research, treatment and education of diabetes and related disorders. 2020:1-11https://doi.org/10.1007/s13300-020-00829-7.

26. Maddaloni E, Coraggio L, Pieralice S, Carlone A, Pozzilli P, Buzzetti R. Effects of COVID-19 Lockdown on Glucose Control: Continuous Glucose Monitoring Data From People With Diabetes on Intensive Insulin Therapy. Diabetes Care. 2020; https://doi.org/10.2337/dc20-0954.

27. Palmer K, Monaco A, Kivipelto M, Onder G, Maggi S, Michel JP, et al. The potential long-term impact of the COVID-19 outbreak on patients with non-communicable diseases in Europe: consequences for healthy ageing. Aging Clin Exp Res. 2020:16https://doi.org/10.1007/s40520-020-01601-4.

28. Dekker J, Buurman BM, van der Leeden M. Exercise in people with comorbidity or multimorbidity. Health psychology : official journal of the Division of Health Psychology, American Psychological Association. 2019; 38:822-

30https://doi.org/10.1037/hea0000750.

29. Scicali R, Di Pino A, Piro S, Rabuazzo AM, Purrello F. May statins and PCSK9 inhibitors be protective from COVID-19 in familial hypercholesterolemia subjects? Nutrition, metabolism, and cardiovascular diseases : NMCD. 2020; https://doi.org/10.1016/j.numecd.2020.05.003.

30. Fan R, Xu M, Wang J, Zhang Z, Chen Q, Li Y, et al. Sustaining Effect of Intensive Nutritional Intervention Combined with Health Education on Dietary Behavior and Plasma Glucose in Type 2 Diabetes Mellitus Patients. Nutrients. $2016 ; 8$. https://doi.org/10.3390/nu8090560.

\section{Tables}

Table 1. Demographic Characteristics of participants

\begin{tabular}{|c|c|c|c|c|c|c|c|}
\hline Characteristics & $\begin{array}{l}\text { Participants } \\
\text { with TC } \\
\square n=3379 \square\end{array}$ & $\begin{array}{l}\text { Participants } \\
\text { with LDLC } \\
\square n=3341 \square\end{array}$ & $\begin{array}{l}\text { Participants } \\
\text { with TG } \\
\square \mathrm{n}=3381 \square\end{array}$ & $\begin{array}{l}\text { Participants } \\
\text { with UA } \\
\square n=3364 \square\end{array}$ & $\begin{array}{l}\text { Participants } \\
\text { with HbA1 } \\
\square \mathrm{n}=532 \square\end{array}$ & $\begin{array}{l}\text { Participants } \\
\text { with BMI } \\
\square \mathrm{n}=445 \square\end{array}$ & $\begin{array}{l}\text { Participants } \\
\text { with BP } \\
\square \mathrm{n}=463 \square\end{array}$ \\
\hline $\begin{array}{l}\text { Age, median } \\
\text { (IQR) } \\
\text {-Young, n(\%) } \\
\text {-Middle-aged, } \\
\text { n(\%) }\end{array}$ & $\begin{array}{l}56.0 \\
(42.0,66.0) \\
979(29.0 \% \\
1436(42.5 \%)\end{array}$ & $\begin{array}{l}56.0 \\
(42.0,66.0) \\
966(28.9 \%) \\
1417(42.4 \%)\end{array}$ & $\begin{array}{l}56.0 \\
(42.0,66.0) \\
980(29.0 \% \\
1438(42.5 \%)\end{array}$ & $\begin{array}{l}55.0 \\
(41.0,66.0) \\
994(29.5 \% \\
1368(40.7 \%)\end{array}$ & $\begin{array}{l}64.0 \\
(55.0,70.0) \\
40(7.5 \% \square \\
249(46.8 \% \square\end{array}$ & $\begin{array}{l}30.0 \\
(27.0,35.0) \\
336(75.5 \% \square \\
100(22.5 \% \square\end{array}$ & $\begin{array}{l}35.0 \\
(30.0,44.0) \\
352(76.0 \% \square \\
102(22.0 \% \square\end{array}$ \\
\hline $\begin{array}{l}\text {-Aged, n(\%) } \\
\text { Male, n(\%) }\end{array}$ & $\begin{array}{l}964(28.5 \% \\
1558(46.1 \%) \\
\end{array}$ & $\begin{array}{l}958(28.7 \%) \\
1551(46.4 \%\end{array}$ & $\begin{array}{l}963(28.5 \% \square \\
1557(46.1 \%)\end{array}$ & $\begin{array}{l}1002(29.8 \%) \\
1527(45.4 \%)\end{array}$ & $\begin{array}{l}(45.7 \% \square \\
(62.2 \% \square\end{array}$ & $\begin{array}{l}9(2.0 \% \square \\
175(39.3 \% \square\end{array}$ & $\begin{array}{l}9(1.9 \% \square \\
184(39.7 \% \square\end{array}$ \\
\hline
\end{tabular}

Data were expressed as the the median (IQR) for continuous variables. Categorical variables were plotted as the number (percentage).

Table 2. Comparison of baseline and follow-up levels of metabolic indicators associated with NCDs

\begin{tabular}{|c|c|c|c|}
\hline Measurements & Baseline, median (IQR) & Follow-up, median (IQR) & P Value \\
\hline $\mathrm{TC}, \mathrm{mmol} / \mathrm{L}(\mathrm{n}=3379)$ & $4.71(4.05,5.43)$ & $4.73(4.05,5.46)$ & $0.019^{*}$ \\
\hline $\mathrm{LDLC}, \mathrm{mmol} / \mathrm{L}(\mathrm{n}=3341)$ & $3.04(2.44,3.70)$ & $3.00(2.40,3.67)$ & 0.169 \\
\hline $\mathrm{TG}, \mathrm{mmol} / \mathrm{L}(\mathrm{n}=3381)$ & $1.25(0.87,1.81)$ & $1.29(0.91,1.88)$ & $<0.001^{*}$ \\
\hline UA, umol/L $(n=3354)$ & $\begin{array}{l}327.0 \\
(271.0,389.0)\end{array}$ & $\begin{array}{l}330.0 \\
(272.0,397.0)\end{array}$ & $<0.001^{*}$ \\
\hline $\mathrm{HbA1c}, \% \square \mathrm{n}=532$ ) & $6.50(6.10,7.20)$ & $6.50(6.10,7.30)$ & $0.013^{*}$ \\
\hline $\mathrm{BMI}, \mathrm{kg} / \mathrm{Q} \mathrm{n}=445)$ & $22.88(20.89,24.97)$ & $22.86(20.72,24.88)$ & 0.976 \\
\hline $\mathrm{SBP}, \mathrm{mmHg}[\mathrm{n}=463$ ) & $120.0(111.0,130.0)$ & $120.0(111.0,129.0)$ & 0.896 \\
\hline $\mathrm{DBP}, \mathrm{mmHg} \square \mathrm{n}=463)$ & $73.0(67.0,81.0)$ & $73.0(67.0,81.0)$ & 0.724 \\
\hline
\end{tabular}

Page 8/9 
Data were expressed as the the median (IQR) for continuous variables.

* indicates statistical significance difference $(p<0.05)$. 